\title{
A música na sala de aula: reflexões sobre sexualidade na educação básica
}

\author{
Karina Nonato FERNANDES ${ }^{1}$ \\ Fábio Tadeu REINA ${ }^{2}$ \\ Valéria M. N. F. MOKWA ${ }^{3}$
}

\section{Introdução}

A música auxilia o aprendizado de maneira lúdica e espontânea e o educador que utiliza deste recurso encontra diversos caminhos para a construção do saber. Podemos incluir a música em qualquer que seja o tema trabalhado em sala de aula, mas ainda percebemos que a maioria dos professores apresenta dificuldades de incluir essa ferramenta em sua prática pedagógica alegando ausência do dom musical; ou por não atribuir a esse instrumento contribuições nas apresentaçóes dos conteúdos e na aprendizagem do educando.

A educação devido o seu papel socializador auxilia e possibilita o desenvolvimento do aluno devido sua particularidade de promover a integração e participação do educando no grupo social, visando o progresso do mesmo. A música

1 Musicoterapeuta. Mestranda em Educação Sexual. UNESP - Universidade Estadual Paulista. Faculdade de Ciências e Letras - Departamento de Psicologia da Educação. Araraquara - SP - Brasil. 14800-901 - karinamusicoterapeuta@yahoo.com.br

2 Pós-Doutorado em Educação. UNESP - Universidade Estadual Paulista. Faculdade de Ciências e Letras - Departamento de Psicologia da Educação. Araraquara - SP Brasil. 14800-901 - ftreina@hotmail.com

3 Doutora em Educação Escolar. Membro efetivo do Núcleo de Estudos da Sexualidade (NUSEX). UNESP - Universidade Estadual Paulista. Faculdade de Ciências e Letras. Araraquara - SP - Brasil. 14800-901 - valeriamokwa@gmail.com 
utilizada na educação é um subsídio de grande importância, propicia à aprendizagem a formação do desenvolvimento cognitivo do educando, promove inúmeros benefícios na formação do ser humano, considerando os aspectos biopsicossociais como lembra Costa e Valle (1969 p. 13): "A música é excelente recurso para auxiliar o desenvolvimento da criança [...] além de levar ao desenvolvimento geral, auxilia particularmente a coordenação motora, a acuidade auditiva, a acuidade visual, a memória, a atenção, entre outras."

Com a intenção de mostrar aspectos considerados fundamentais e importantes na formação docente, pois irá participar diretamente da formação da criança e no seu desenvolvimento biopsicossocial e cognitivo, o presente artigo buscou apreender acerca da música que precede a educação formal e está em toda a formação do desenvolvimento humano desde sua concepção, inclusive na formação docente, que é um ser social que está em conexão com os possíveis caminhos que a música possa desenvolver na sala de aula. Utilizamos a pesquisa bibliográfica para fundamentar esse trabalho, bem como baseando-se em práticas discursivas realizada pelos autores em diferentes grupos sociais, a respeito da temática em voga.

\section{Conceituando a música e seus aspectos gerais}

Para entender como deve ocorrer a aplicação da música no universo escolar, primeiramente é preciso conhecer a diferença que há entre musicalização, musicalidade e educação musical.

MUSICALIDADE: É a tendência ou inclinação do indivíduo para a música. Quanto maior a musicalidade, mais rápido será seu desenvolvimento. Revela-se, muitas vezes, na infância e independe de formação acadêmica;

MUSICALIZAÇÁO: Processo cognitivo e sensorial que envolve o contato com o mundo sonoro e a percepção rítmica, melódica e harmônica, podendo ocorrer intuitivamente ou por intermédio de orientação. Intuitiva ou formal, a musicalização não significa necessariamente o ato de compor, cantar ou tocar um instrumento, também não requer conhecimento de teoria musical. É, portanto, um conhecimento que tão mais profundo será quanto maior for à convivência experimental com a música;

EDUCAÇÃO MUSICAL: É a educação formal da música realizada por um profissional capacitado, incluindo os elementos da música e a criatividade, permitindo que a criança tenha o conhecimento dos conceitos básicos da música e como aplicá-los de forma organizada ou não, para o fazer musical em suas várias possibilidades. 
Então o que é música? A música tal como o homem conhece há tempos e nos é apresentada desde a tenra idade é composta por som e ritmo. Segundo Mário de Andrade (1987 apud MILLECO FILHO, 2001, p.5):

[...] os elementos formais da música, o Som e o Ritmo, são tão velhos como o homem, por estarem presentes nele mesmo, nos movimentos do coração, no simples ato de respirar, no caminhar, nas mãos que percutem e na voz que produz o som. Quando o homem se percebe como um instrumento, como um corpo sonoro, e descobre que estes sons podem ser organizados, nasce a música. Começa, ele, então, a manejá-los, combiná-los, convertendo-os em matéria nova, em um fantástico veículo expressivo.

A música, assim como nosso organismo é composta de elementos que a organizam de forma que possamos ter uma audição prazerosa do som. Através da combinação dos elementos musicais, como a dinâmica, pulsação, intensidade, entre outros, temos diversas músicas e estilos musicais.

Para Murray Schafer (1991, p.13) que consagrou a expressão (soundscape) "paisagem sonora", diria que hoje em dia, temos muitos sons que estão diretamente ligados ao nosso cotidiano, como o tráfego, rádios, celulares, entre outras tantas sonoridades que nosso cérebro seria incapaz de captar e digerir. $\mathrm{O}$ que fica, entấo, dessa paisagem sonora para as crianças? Como elas recebem e desenvolvem essa paisagem sonora dentro de si?

Precisamos estar atentos para as sonoridades que cada criança traz para sala de aula, através das brincadeiras, falas, canto, ambiente sonoro que ela está inserida, de forma que possamos contextualizar essas expressóes e transformar em brincadeiras musicais que despertam vários aspectos biopsicossociais, como a lateralidade, a fala, a coordenação motora, além do momento lúdico que traz a criatividade e espontaneidade de cada criança.

Willems (1970, p.7-8) confirma esse conceito ao afirmar que:

[...] a música é considerada um fator importante da formação da personalidade humana; não apenas porque ela cria um clima particularmente favorável ao despertar das faculdades criadoras, mas ainda porque pode vivificar a maioria das faculdades humanas e favorecer o seu desenvolvimento.

Para delimitarmos melhor a importância da música na escola, vamos ter como base o que está escrito nos Parâmetros Curriculares Nacionais (BRASIL, 1997, p.55):

Para que a aprendizagem da música possa ser fundamental na formação de cidadãos é necessário que todos tenham a oportunidade de participar ativamente como ouvintes, intérpretes, compositores e improvisadores, dentro 
e fora da sala de aula. Envolvendo pessoas de fora no enriquecimento do ensino e promovendo interaçáo com os grupos musicais e artísticos das localidades, a escola pode contribuir para que os alunos se tornem ouvintes sensíveis, amadores talentosos ou músicos profissionais. Incentivando a participaçáo em shows, festivais, concertos, eventos da cultura popular e outras manifestaçôes musicais, ela pode proporcionar condiçóes para uma apreciação rica e ampla onde o aluno aprenda a valorizar os momentos importantes em que a música se inscreve no tempo e na história.

Podemos considerar que música é toda sonoridade trazida pelas crianças em sala de aula como forma criativa através do seu corpo, de sons do ambiente em que vive, dos instrumentos musicais e músicas gravadas, de acordo com o contexto de cada época e cultura que esta encontra inserida e a escola tem importante papel de estimular a criança e seu desenvolvimento explorando, valorizando e contextualizando seus conhecimentos musicais.

No livro Música na Educação Infantil, Teca Alencar de Brito (2003) ressalta que o fazer musical ocorre "por meio de dois eixos - a criação e a reprodução que garantem três possibilidades de ação: a interpretação, a improvisação e a composição."

Heitor Villa-Lobos (1887-1959) foi precursor da ideia da música na sala de aula que atualmente com a Lei $n^{\circ} 11.769$ em agosto de 2008, volta ser obrigatória na grade curricular dos ensinos fundamental e médio. Mas a lei não é clara quanto ao profissional que pode aplicar essa educação musical, ficando a mercê de cada instituição em treinar ou contratar um profissional que tenha a capacidade de colocar a música e seus vários aspectos, o que culmina geralmente na utilização da música de forma apenas recreativa.

Daí, esperarmos que a "música na escola" tão reivindicada, não se confunda com um fazer musical pedagogicamente, descompromissado, de lazer e passatempo, nem que a educaçáo musical seja aprisionada pela educaçáo artística e confundida com "história da música" ou outras estórias de nomes e datas. (ALLUCCI \& ASSOCIADOS COMUNICAÇÓES, 2012, p.44).

Precisamos sim, da música na escola. Mas, faz-se mister que ela seja com qualidade de ensino, que deva ser realizada por profissionais qualificados e com conteúdos que realmente, despertem as faculdades perceptivas, sócio-interativas, emocionais, críticas e reflexivas dos alunos.

\section{A sociedade e seus habitus: as influências da música}

A música acompanha cada homem desde antes de seu nascimento até o momento em que morre. É utilizada como elemento de expressão individual 
e coletiva e se insere em quase todas as atividades do homem (BENEZON, 1988).

Existem sons que estão dentro de nós como, por exemplo, a respiração, batimentos cardíacos, sons intestinais, e nos acompanham por toda vida, além dos sons gravados em nós desde a gestação, como a voz da mãe, do pai, entre outros.

Combinar sons que estão dentro de nós e a ao nosso redor pode tornar-se música, como diz Schafer (1991) que a música é uma organização de sons com a intenção de ser ouvida, para tanto, antes de combiná-los, é necessário percebê-los para depois organizá-los.

Portanto, não há regras para a música e sua composição, a combinação dos elementos musicais está aberta para a criação e organização conforme a percepção sonora de cada um e como a interpreta e sente sua música como melhor lhe convém.

$\mathrm{Na}$ atualidade, nos deparamos cada vez mais com sons tecnológicos e que, nos trazem para perto das informaçóes e desenvolvimento global.

Cada sociedade traz sua marca sonora, sua identidade que indica sua forma de vida, seus costumes e hábitos, assim como confirma Schafer (2011, p.27):

O termo marca sonora deriva de marco e se refere a um som da comunidade que seja único ou que possua determinadas qualidades que o tornem especialmente significativo ou notado pelo povo daquele lugar.

Para tanto, precisamos trazer à tona essa percepção sonora ambiental em que vivemos, para que possamos entender melhor esse universo sonoro identificando os pontos positivos e negativos, incluindo sempre momentos mais prazerosos, no que se refere aos sons cotidianos.

É importante que a criança possa apropriar-se dos sons que a cerca, construindo uma paisagem sonora mais agradável e menos agressiva, principalmente para quem está situado dentro dos grandes centros urbanos, onde cada vez mais temos uma poluição sonora, com ruídos que podem ter consequências muito graves no futuro de cada ser humano.

Mesmo que genericamente, de alguma forma, todos sabem que a música tem o poder de relaxamento, evoca emoçóes, libera endorfinas e traduz diretamente, momentos que marcaram nossas vidas.

De acordo com o neurocientista Mauro Muszkat, ele refere que:

Há uma especialização hemisférica para a música, no sentido do predomínio do lado direito para a discriminaçấo da direção das alturas (contorno melódico), do conteúdo emocional da música e dos timbres (nas áreas 
temporais e frontais). (ALLUCCI \& ASSOCIADOS COMUNICAÇÓES, 2012, p.68).

É fato que a música representa muitas classes sociais. No Brasil, a influência dos negros, dos europeus e índios, trouxe uma forte diversidade cultural e musical. Hoje em dia, isso se traduz em misturas como samba-rock, sertanejo universitário e até mesmo, o funk, que teve modificações ao longo dos tempos.

Coelho e Favaretto (2010) destacam o funk como gênero musical nascido nos Estados Unidos, por músicos negros, na década de 1960, tendo como um grande cantor e compositor, James Brown.

Porque tantas modificaçôes, ao longo dos tempos, dentro do mesmo gênero musical?

Não podemos esquecer a influência dos veículos de comunicações e o capital como geração de mais capital, a onda da massificação para obter lucros indiscriminados.

O fato é que temos uma violência simbólica (BOURDIEU, 1997), ou seja, é uma guerra unilateral, a mídia atacando a sociedade, as crianças, com os modismos, os produtos, os brinquedos, o sonho do ter, do possuir, de ser feliz ao comprar o lançamento deste ou daquele brinquedo, saber cantar e dançar essa ou aquela música que toca nos programas de auditório. É a busca do ser humano pelo pertencimento do seu grupo ou realidade social que está inserido.

Cabe, então, a nós educadores, revelar o que está por traz das propagandas, dos programas de televisão, dos produtos oferecidos pela mídia, das letras das músicas mais impostas nos meios de comunicação, como forma de proteção das crianças que apenas estão nesse meio, que induz ao consumo desenfreado e sem a mínima consciência dessa forma de violência.

Com tantas influencias que a música abarca, não podemos deixar de entrar nas questóes da sexualidade que na atualidade através das músicas como o funk, o sertanejo universitário, trazem à tona essa sexualidade desde a infância, principalmente pelos veículos de comunicação.

A partir do momento em que uma mulher engravida, inicia-se uma Educação Sexual com a ansiedade em distinguir o nosso sexo, a princípio. Após essa definição, cria-se um mundo das possibilidades como o nome a ser dado, a cor do quarto, a aparência, enfim, uma nova vida já previamente, definida, ou melhor dizendo, hetero-normativamente definida.

Há modelos pré-estabelecidos de decoração para meninas e para meninos. As cores, os temas dos desenhos animados, os brinquedos, a forma como educar cada gênero, a princesa e o "macho garanhão", ainda se perpetua no nosso século. 
A Educação Sexual está arraigada nos padrôes impostos pela sociedade, como um legado histórico, segundo Bourdieu, (2007, p.185) "O habitus, produto de uma aquisição histórica, é o que permite a apropriação do legado histórico.”

Bourdieu (2007, p. 185-186) esclarece que:

O herdeiro herdado, apropriado à herança, não tem necessidade de querer, isto é, de deliberar, escolher e decidir conscientemente, para fazer o que é apropriado, o que convém aos interesses da herança, de sua conservaçáo e de sua ampliação. A rigor, ele pode nem saber o que faz ou que diz e, náo obstante, acabar fazendo ou dizendo exatamente conforme as exigências de perpetuação da herança.

Bourdieu nos ressalta o quanto somos influenciados pela nossa educação familiar, que é influenciada pela sociedade, e essa influenciada, ou melhor, dizendo, gerenciada pela classe dominante, de acordo com a hierarquia social vigente e o capitalismo.

Para tanto, de acordo com essas considerações, a Educação Sexual informal, familiar, social, induz a uma Educação Sexual heterossexual, em que a menina usa vestido rosa e o menino calça azul, e alguma situação adversa é rapidamente repreendida e abafada. É o corpo socializado, moldado, direcionado para padróes de comportamentos de acordo com o gênero ao qual pertence.

Entram em vigor, as condiçóes de existência, ou seja, o estilo de vida que o indivíduo terá como verdade, como parte integradora da sociedade e do seu pertencimento, é o capital cultural, o capital simbólico, o capital legítimo. Enfim, tudo o que é passado como verdade através do núcleo familiar e social.

Tudo tende a parecer natural, dentro das normas e dos padróes socialmente aceitos, como podemos perceber em Bourdieu (2011, p.164):

Os estilos de vida são, assim, os produtos sistemáticos dos habitus que, percebidos em suas relaçóes mútuas segundo os esquemas dos habitus, tornamse sistemas de sinais socialmente qualificados - como "distintos", "vulgares", etc. A dialética das condiçóes e dos habitus é o fundamento da alquimia que transforma a distribuição do capital, balanço de uma relação de forças, em sistema de diferenças percebidas, de propriedades distintivas, ou seja, em distribuição de capital simbólico, capital legítimo, irreconhecível em sua verdade objetiva.

Estes padrôes de comportamento, estilo de vida, em relação à educaçáo sexual informal, é tão arraigada que quando perguntamos a respeito de como é trabalhada a educação sexual na escola, as professoras não conseguem responder objetivamente. Parece que há um bloqueio ao falar sobre sexo e sexualidade, e 
como ainda falta informação e preparo. Elas preferem reproduzir o cotidiano e o hábito social, o que é aceito e o que todos pregam como verdade.

E dentro da sala de aula, como se processa a educação sexual que é trazida pela criança, a partir desses modelos pré-estabelidos? Será que os docentes estão preparados para essa temática?

Werebe (1981, p. 107) diz que:

O fato de que o professor não tenha consciência dessa influência sobre a vida sexual dos alunos é grave, pois a açáo que desempenha fica de certa forma fora de seu controle. Por sua vez, o aluno também não tem a consciência dessa influência e, por isso, não se "prepara" para recebê-la e não pode enfrentá-la diretamente.

A qualidade de ensino é vista, apenas, pelo lado do conteúdo das ciências, sendo esquecido o conteúdo das emoçóes, e a música e a sexualidade traz a tona essas emoçóes que não são relevantes para a sociedade na infância, porém, que influenciam as mesmas e podem trazer consequências futuras em decisóes de sua vida adulta, como por exemplo, quando as crianças cantam e dançam músicas que incentivam o sexo e possivelmente seu interesse cada vez mais antecipado e com isso a iniciaçáo sexual cada vez mais cedo.

Além disso, o meio em que habitam, influencia nessas emoções, o capital social, cultural herdado de cada criança, vai de encontro com sua aprendizagem e certamente, com a formação de seus pensamentos e atitudes.

Quantas crianças conseguem participar de shows infantis, teatros, visitarem museus? Mas o funk, a todo instante ouve-se na mídia e dita um modelo de machismo incutido nas letras e nas danças, reproduzindo a mulher objeto que é construída historicamente desde da nossa colonização.

Isso massifica e coloca a realidade dessa criança, que constrói uma identidade sexual machista e capitalista.

Bourdieu (2007, p. 275), entáo, nos explica que:

Quando os poderes estáo desigualmente distribuídos, em vez de se mostrar como um universo de possíveis igualmente acessíveis a todo o sujeito possívelpostos a ocupar, estudos a fazer, mercados a conquistar, bens a consumir, propriedade a trocar, etc.-, o mundo econômico e social se apresenta como universo balizado, semeado por injunçôes e proibiçóes, por signos de apropriação e exclusão, por sentidos obrigatórios ou barreiras instransponíveis, numa palavra, profundamente diferenciado, sobretudo conforme o grau em que propóe oportunidades estáveis e de molde a favorecer e a preencher expectativas estáveis. Sob suas diferentes espécies, o capital é um conjunto de direitos de preempçáo sobre o futuro; garante a alguns o monopólio de certos 
possíveis que, no entanto, encontram-se oficialmente garantidos a todos (como o direito à educação).

As igualdades não são para todos. As fraçôes de classe são distintas e cada um luta com as armas que tem. Teremos sempre os distanciamentos das possibilidades de ascensão econômica, mas ainda pior, o distanciamento da ascensão cultural, pois a massa se rende aos domínios da mídia e das políticas, ainda, nos tempos de hoje, do "Páo e do "Circo", cada vez mais, com espetáculos e programas televisivos que estipulam a música, a moda, o comportamento, como os programas de reality show e os espetáculos de arrecadaçáo monetárias para os menos favorecidos (Criança Esperança, Teleton, etc), e ainda, com a participação da classe artística que empobrece nossa música brasileira, tanto na qualidade musical quanto na qualidade semântica das cançóes.

Portanto, trazer para a sala de aula, desde a tenra infância até a formação profissional, a Educação Musical e a Educação Sexual, é de extrema importância para que possamos trazer a qualidade de ensino, de cultura, de consciência para a formação de cidadãos, que seja de qualquer classe social, possa ter alguma condição de estar inserido em contextos que são privilégio de poucos.

\section{Considerações finais}

$\mathrm{Na}$ busca de compreender a influência da música nos meios sociais, principalmente na escola, esse artigo contemplou autores que referencia a importância da música para o desenvolvimento da criança, principalmente dentro da sala de aula, no entanto, refletiu sobre aspectos, que na atualidade, influenciam sobremaneira essas crianças na questão da sexualidade, através de músicas que estão impressas como marca social.

Pensando no professor, e na sua formação pessoal e profissional, não podemos esquecer que este ainda, é um ser social, que carrega a herança cultural advindo da sociedade e de seu meio, o que culmina a influenciar na sua prática pedagógica. Nesse sentido é importante os cursos de formação que propóe espaços para refletir a música e a sexualidade no contexto escolar.

Percebemos cada vez a influência da sexualidade através da música, o que nos incita a busca de reflexóes a respeito de nosso valores e atuação profissional, para que a criança possa ter seu desenvolvimento de uma forma geral com base na reflexão, construção crítica e reflexiva acerca dessas temáticas aqui propostas. 


\section{REFERÊNCIAS}

ALMEIDA, M. B. de, PUCCI, M. D. Outras terras, outros sons. São Paulo: Callis, 2002. ALLUCCI \& ASSOCIADOS COMUNICAÇÕES. A música na escola. São Paulo, 2012 BENEZON, R. Teoria da musicoterapia. Tradução de Ana Sheila M. de Uricoecheal. São Paulo: Summus, 1988.

BOURDIEU, P. A Distinção: crítica social do julgamento. 2.ed. rev. Porto Alegre: Zouk, 2011.

. Meditaçóes pascalianas. 2.ed. Rio De Janeiro: Bertrand Brasil, 2007.

. A dominaçáo masculina. Tradução de Maria Helena Kühner. 2.ed. Rio de Janeiro: Bertrand Brasil, 2002. 1997.

Sobre a televisão. Tradução de Maria Lúcia Machado. Rio de Janeiro: Jorge Zahar,

O poder simbólico. Rio de Janeiro: Bertrand Brasil, 1989.

. Esboço de uma teoria da prática. In: ORTIZ, R. (Org.). Pierre Bourdieu: sociologia. São Paulo: Ática, 1983. p.46-81.

. Sociologia. Organização da coletânea por Renata Ortiz. São Paulo: Ática, 1983.

BRASIL. Ministério da Educação. Secretaria de Educação Fundamental. Parâmetros curriculares nacionais: apresentação dos temas transversais: ética. Brasília, 1997. Disponível em: <portal.mec.gov.br/seb/arquivos/pdf/livro081.pdf>. Acesso em: 20 set. 2015.

BRITO, T. A. de. Música na educaçáo infantil: propostas para a formação integral da criança. São Paulo: Peirópolis, 2003.

COElHO, M.; FAVARETTO, A. Batuque Batuta: música na escola, 5o ano. São Paulo: Saraiva, 2010.

COSTA, N. M. da; DEL VALLE, E. A. Música na escola primária. Rio de Janeiro: Jose Olympio, 1969.

FOUCAULT, M. História da sexualidade. 11.ed. Rio de Janeiro: Graal, 1988. (A vontade de saber ; v. 1).

LACERDA, O. Compendio de teoria elementar da música. São Paulo: Ricordi Brasileira, 1961.

MILLECO FILHO, L. A. Musicoterapia, cantos e cançóes. Rio de Janeiro: Enelivros, 2001.

RUUD, E. (Org.). Música e saúde. São Paulo: Summus, 1990.

SCHAFER, R. M. A afinaçáo do mundo: uma experiência pioneira pela história passada e pelo atual estado do mais negligenciado aspecto do nosso ambiente: a paisagem sonora. São Paulo: Ed. da UNESP, 2011.

O ouvido pensante. São Paulo: Ed. da UNESP, 1991. 
WILLEMS, E. As bases psicológicas da educação musical. Edição patrocinada pela Fundação Calouste Gulbenkian. Bienne: Ediçôes Pró-Musica, 1990.

WEREBE, M. J.G. Educação sexual: instrumento de democratização ou de mais repressão? Cadernos de Pesquisa, São Paulo, n.36, p. 99-110, fev. 1981. 


\title{
Resumo
}

A música na sala de aula: reflexóes sobre sexualidade na educação básica

O presente artigo buscou trazer a reflexão acerca da música na sala de aula e discutir sua influência para sexualidade. Utilizamos a pesquisa bibliográfica para fundamentar esse trabalho, bem como baseando-se em práticas discursivas realizada pelos autores em diferentes grupos sociais, a respeito da temática em voga. Percebemos cada vez mais a influência da sexualidade através da música, o que nos incita a busca de reflexôes a respeito de nosso valores e atuação profissional, para que a criança possa ter seu desenvolvimento de uma forma geral com base na reflexão, construção crítica e reflexiva acerca dessas temáticas aqui propostas.

Palavras-chave: Música. Educação sexual. Formação profissional.

\begin{abstract}
Music in the classroom: reflections on sexuality in basic education

This paper aims to bring reflections on music in the classroom and discuss their influence on sexuality. We use the literature to support this work and based on discursive practices carried out by the authors in different social groups, on the theme in vogue. We realize more and more the influence of sexuality through music, which urges us to search reflections about our values and professional performance, so that the child may have development in general based on reflection, critical and reflective construction about these themes proposed here.
\end{abstract}

Keywords: Music. Sex education. Professional qualification. 